\title{
AÇÃO RESCISÓRIA E HOMOLOGaÇãO de TRANSAÇãO (*)
}

\author{
Prof. GALENO LACERDA
}

Catedrátirco da Faculdade de Direito de Porto Alegre, da Universidade Federal do Rio Grande do Sul.

1. Sem dúvida, devemos a LIEBMAN, o clássico da coisa julgada e dos efeitos da sentença, as noções mais lúcidas e precisas sobre esse importantíssimo tema ("Eficácia e Autoridade da Sentença", 1945', ps. 35 e segs., 49 e segs.)'.

A decisão judicial, segundo ele, se ligam três conceitos básicos e distintos: imperatividade, imutabilidade dentro do processo e imutabilidade fora do processo.

A imperatividade consttivi o efeito uniforme de todas as decisões judiciais, como atos de autoridade pública, qualquer que seja seu conteúdo. O comando delas emanado possui eficácia imperativa, nos limites da lei, independentemente do trânsito em julgado.

Essa eficácia imperativa, a atuar desde logo, a partir da publicação do ato, é que explica a justifica, por exemplo, a execução provisória de sentença, antes de passada em julgado, quando o recurso não tiver efeito suspensivo.

O trânsito em julgado, ou preclusão, provoca dois outros efeitos: um, presente em todos os processos judiciais, caracterizado pela imutalidade ou inimpugnabilidade da decisão no processo em que foi proferida, efeito que se denomina "coisa julgada formal", ou simplesmente "preclusão"; e outro, eventual, consistente na imutabilidade da sentença fora do processo, quando esta julga o mérito da lide e, por isso, chamado "coisa julgada material".

Quando uma decisão transitar apenas formalmente em julgado, ela não impede que se renovem a ação ou o pedido em outro processo.

(*) Conferência proferida em Curitiba no dia 15 de setembro de 1978, no Ciclo de Palestras de Direito Processual Civil, promovido pelo Dept. ${ }^{\circ}$ de Direito Civil e Processual Civil da UFPr., em homenagem ao Prof. Egas Dirceu Moniz de Aragão, por motivo de sua jubilaçăo consentida. 


\title{
AÇĀO RESCISÓRIA E HOMOLOGAÇÃO DE TRAMSAÇÃO (")
}

\author{
Prof. Galeno LACERDA \\ Catedrátirco da Faculdade de Direito de Porto \\ Alegre, da Universidade Federal do Rio Gran- \\ de do Sul.
}

1. Sem dúvida, devemos a LIEBMAN, o clássico da coisa julgada e dos efeitos da sentença, as noções mais lúcidas e precisas sobre esse importantíssimo tema ("Eficácia e Autoridade da Sentença", 1945', ps. 35 e segs., 49 e segs.)'.

A decisão judicial, segundo ele, se ligam três conceitos básicos e distintos: imperatividade, imutabilidade dentro do processo e imutabilidade fora do processo.

A imperatividade consttivi o efeito uniforme de todas as decisões judiciais, como atos de autoridade pública, qualquer que seja seu conteúdo. O comando delas emanado possui eficácia imperativa, nos limites da lei, independentemente do trânsito em julgado.

Essa eficácia imperativa, a atuar desde logo, a partir da publicação do ato, é que explica a justifica, por exemplo, a execução provisória de sentença, antes de passada em julgado, quando o recurso não tiver efeito suspensivo.

O trânsito em julgado, ou preclusão, provoca dois outros efeitos: um, presente em todos os processos judiciais, caracterizado pela imutalidade ou inimpugnabilidade da decisão no processo em que foi proferida, efeito que se denomina "coisa julgada formal", ou simplesmente "preclusão"; e outro, eventual, consistente na imutabilidade da sentença fora do processo, quando esta julga o mérito da lide e, por isso, chamado "coisa julgada material".

Quando uma decisão transitar apenas formalmente em julgado, ela não impede que se renovem a ação ou o pedido em outro processo.

(*) Conferência proferida em Curitiba no dia 15 de setembro de 1978, no Ciclo de Palestras de Direito Processual Civil, promovido pelo Dept. ${ }^{\circ}$ de Direito Civil e Processual Civil da UFPr., em homenagem ao Prof. Egas Dirceu Moniz de Aragão, por motivo de sua jubilação consentida. 
Isto pode ocorrer em três hipóteses:

a) quando se tratar de decisão terminativa sem julgamento do mérito, também denominada "sentença" pelo Código atual (art. 162, $\left.\S 1 .^{\circ}\right)$, caso em que a ação poderá ser renovada se não ocorrer perempção (art. 268, § único);

b) quando o mérito da causa, pela transcendência de seu valor humano (alimentos, guarda de filhos, etc.), excluir a definitividade permanente, fora do processo, eis que os motivos sociais e políticos que justificam a imutabilidade do julgado devem naquilo que o Códbgo denomina de "relação jurídica cntinuativa" (art. 471, 1);

c) quando se tratar de mera atuação da chamada "jurisdição voluntária", caso em que o pedido eventualmente indeferido, em decisão preclusa, poderá ser renovado em outro processo.

Em qualquer dessas 'hipóteses, não há necessidade de se desconstituir previamente $\circ$ julgado, para que se ingresse com a nova ação ou p£dido perante $\circ$ respectivo juízo competente de primeiro grau. Este oficiará sem nenhum empecilho, uma vez que a preclusão do juízo anterior se esgotou no processo findo, sem força para impedir novo pronunciamento.

2. Diversa, inteiramente diversa é a situação que ocorre com a sentença de mérito tornada imutável fora do processo pela coisa julgada material.

Esse efeito é próprio tão só dos atos jurisdicionais de mérito. Os atos administrativos, como os provindos da impropriamente dita "jurisdição voluntária", não o possuem.

Isto significa que, para se obter em outro processo o reexame da causa, será indispensável desconstituir-se previamente, através de ação própria, chamada "rescisória", a coisa julgada material, isto é, a imutabilidade da sentença fora do processo, nos limites dos pressupostos excepcionais a que o Código sujeita essa rescisão.

Tudo quanto se disse até aqui constitui noção óbvia e elementar de direito processual civil, pertinente a distinções objetivas e científicas de caráter definitivo, que não podem ser ignoradas ou suprimidas.

3. A transação, a que a conciliação se equipara (art. 447, § único, do C.P.C.), possui natureza contratual. Significa acordo de vontades entre os interessados para "prevenirem ou terminarem o litígio mediante concessões mútuas" (art. 1.025 do Código Civil). Constitui fato extintivo da lide, potencial atual. 
Em que pesem as restrições de certa doutrina, temos a firme convicção de que a única maneira de distinguirmos a atividade jurisdicional da administrativa exercida pelo juiz no processo consiste no apelo à primitiva intuição de CARNELUTTI, que fez da lide a pedra de toque dessa distinção. Da célebre polêmica por ele mantida com CALAMANDREI (Rív. di Dir. Proc. Civ., 1928), resultou para os estudiosos atentos a conclusão, não do erro de CARNELUTTI, mas, tão só, da necessidade de alargarmos seu conceito de lide, por demais privatista, por abranger apenas o conflito de interesse entre partes.

Feita esta correção, de modo a que nele se compreendam, também, os conflitos com o interesse público ou de ordem pública presentes no processo (como ocorre na ação penal, ou no processo civil inquisitório, por exemplo), torna-se insofismável que a lide, neste sentido amplo, constitui elemento essencial para o verdadeiro conceito de jurisdição.

$\mathrm{Na}$ verdade, a jurisdição, como atividade específica do Poder Judiciário, existe por causa do conflito e para solucioná-lo. Os processualistas, a partir da revolução doutrinária alemã em meados do século passado, se afanaram, com razão, em demonstrar a autonomia da relação jurídica processual em face da material, nem sempre existente no bojo do processo (ação improcedente por inexistir fato constitutivo, ação declaratória negativa, etc.). Como é sabido, toda relação jurídica possui três elementos essenciais: sujeitos, objeto e causa, sendo esta sempre um fato jurídico "lato sensu".

Conseguiram os mestres diferençar nitidamente os suịeitos e o objeto das duas relações: a processual e a material. Mas olvidaramse no terceiro elemento - a causa.

Ora, se as relações são distintas, como na verdade o são, a causa da relação processual há de consistir, forçosamente, em fato jurídico diverso daquele que integra a causa da relação material (contrato, nascimento, morte, etc.). A causa que obriga o juiz a prover, a usar da jurisdição no processo, só pode ser o fato jurídico da lide, do confilto atual ou virtual existente entre as partes. Qualquer que seja a sentença, favorável ou desfavorável ao autor, seu objetivo fundamental será atingido, pela eliminação do litígio que a provocou.

Já se vê que, quando ocorre transação, a eliminação da lide não se dá por ato do juiz, mas mediante acordo das partes, através de contrato onde se manifesta a autonomia de vontades. 
Antiga e sábia doutrina, nascida do direito comum, caracteriza a jurisdição contenciosa (que é a verdadeira) como atividade judicial "inter nolentes" isto é, entre pessoas que não querem a mesma decisão, porque desavindas, em conflito, em lide; ao passo que a impropriamente chamada "jurisdição" voluntária se exerceria "inter volenies", isto é, entre pessoas que querem a mesma coisa, que estão de acordo, que não litigam.

Nestas condições, é evidente que, quando as partés transigem no processo, se tornam "inter volentes" perante o juiz; fazem desaparecer o litígio por ato autônomo da vontade e, com isto, fazem cessar também a jurisdição, porque the eliminam a causa, que é a lide, transformando a atividade ulterior do magistrado em ato meramente formal, sem nenhum conteúdo decisório do litígio, já dedesaparecido.

Ao invés de sentença, haverá, então, simples homologação do acordo.

4. Estas verdades sediças, acolhidas sem divergência pelo Código de 39, pela doutrina e pela jurisprudência sob ele formadas, parecem à primeira vista esbarrar na letra de alguns dispositivos do Código em vigor. Ei-los: de mérito:

"Art. 269. - Extingue-se o processo com julgamento

"III - quando as partes transigirem".

"Art. 485. - A sentença de mériło, transitada em julgado, pode ser rescindida quando: (...)

..."VIII - houver fundamento para invalidar confissão, desistência ou transação, em que se baseou a sentença".

Por sua vez, mantém o Código, no art. 486, a mesma norma que $\circ$ anterior consagrava à ação de rescisão, ou anulatória (art. 800, $\S$ único), dos atos judiciais que dependem, ou não, de sentença homologatória:

"Art. 486. - Os atos judiciais, que não dependem de tentenşa, ou em que esta for meramente homologatória, podem ser rescindidos, como os atos jurídicos em geral, nos termos da lei civiir".

Os primeiros comentadores do novo diploma apressaram-se a proclamar a mudança de critério legal quanto à rescisão de transação judicial. Apesar de ser esta simplesmente homologada, nesșa decisão o Código passara a ver autêntico "julgamento de mérito" 
(art. 269, III), somente atacável mediante ação rescisória (art. 485, VIII), e não mais, como ocorria no Código antigo, através da simples ação ordinária anulatória, própria para rescindir os atos judiciais das partes, homologáveis ou não.

Distinções básicas do direito processual civil, verdades inabaláveis da doutrina, teriam ruído por arte e mágica do novo legislador brasileiro, que transmudara, a seu bel prazer, o quadrado em redondo, o branco em preto, uma simples homologação administrativa em sentença jurisdicional de mérito...

Ora, constitui dogma de hermenêutica que, quando a interpretação literal conduz ao absurdo, devemos desconfiar da interpretação e não do bem senso de legislador, devemos ficar com o espírito e com o sistema, e não com a aparência da letra.

Neste equívoco têm incidido, "data venia", os intérpretes do novo Código.

PONTES DE MIRANDA não consegue superar a aparente antinomia entre os arts. 485, VIII, e 486, e cai em flagrante contradição. Ao comentar o primeiro dispositivo, afirma: "Quanto à transação, não podemos levantar dúvida: a homologação chamou ao processo, como conteúdo de ato sentencial, a transação, e tinha o art. 485, VIII, de fazer incidßnte o art. 485, em vez do art. 486" ("Comentários", VI/330, e "Tratado da Ação Rescisória", 5." ed., 1976, pág. 327), isto é, segundo ele, "o Código de 1973 entendeu que seria caso para se ir, desde logo, com a ação rescisória do art. 485, abstraindo-se do art. 486, a despeito de ter havido homologação" ("Comentários", Vl/328).

Contradiz-se, porém, visivelmente, ao comentar o art. 486: Os atos processuais a que se refere o Código, art. 486, são os atos processuais que "envolvem" declaração de vontade, como a desistência e a transação, o compromisso, a outorga de poderes de procuração feita nos autos, etc". ("Comentários", VI/350).

E a seguir, ao concluir trecho obscuro e confuso sobre a desconstituição do "negócio jurídico transacional", sustenta tese absolutamente inaceitável ao afirmar que "a rescisão por ação ordinária contra a sentença homologatória é de propor-se dentro do prazo preclusivo dos dois anos" ("Comentários", VI/370), chegando, assim, ao ápice da confusão entre ação rescisória e a ordinária do art. 486.

Na verdade, a contradição e obscuridade do texto provêm do rumo tomado pelo intérprete, ao considerar a letra do Código como 
de franca ruptura com os conceitos tradicionais do direito processual a respeito do assunto $A$ tentativa de conciliação em que se empenha só pode gerar confusões inaceitáveis, como se viu acima.

5. BARBOSA MOREIRA também se dobra, mas com relutância, à aparente letra do Código, e propõe difícil e algo hesitante conciliação entre os arts. 485, VIII, e 486.

Depois de recusar-se a admitir a dualidade de meios de impugnação contra a transação homologada - a ação rescisória do art. 485, VIII, e a ordinária de rescisão do art. 486 - mostrando os obsurdos a que conduziria $\circ$ paralelismo dos dois remédios, propõe distinção, "data venia", inadmissível: a ação anulatória do art. 486 caberia no curto espaço de tempo entre a transação judicial e o trânsito em julgado da sentença homologatória, após o que o remédio desconstitutivo adequado seria a ação rescisória ("Comentários", 2.9 ed., V/ 154 a 157).

Em outras palavras, não encontrando outra saída para a aparente contradição dos textos, chega a cogitar da inviável figura de uma ação ordinária incidente sobre processo em curso, desconstitutiva de transação judicial antes da passagem em julgado da homologação.

6. O grande processualista que é LUIS EULÁLIO VIDIGAL rebela-se, francamente, contra $O$ aparente critério, ou falta de critério do Código na matéria, mas não consegue, também, superar a dificuldalde:

"Esses esclarecimentos bastam para evidenciar que a transação não se deveria anular pela ação rescisória dos julgados e sim pela ação ordinária de anulação dos atos jurídicos em geral. 0 Código, entretanto, inovou, permitindo a rescisão de julgado baseado em transação. Esqueceu-se, porém, de que a transação não é seguida de juigamento. Ela própria põe termo ao litígio. Mesmo quando é seguida de homologação, esta última não se rescinde (art. 486) Parece, nessas condições, que melhor teria feito o legislador se dissesse pura e simplesmente que a transação é suscetível de rescisão tal como a sentença passada em julgado". ("Comentários", - VI/148).

JOSEE FREDERICO MARQUES, porém, aceita sem rebeldia o equívoco e sustenta que a homologação de transação está excluída da incidência do art. 486, isto é, sujeita-se à ação rescisória ("Manual", III/710). 
7. ROGERIO LAURIA TUCCI, depois de considerar, com impropriedade, a homologação da transação um "julgamento ántecipado da lide" ("Do Julgamento conforme o Estado do Processo", 1975, p. 137), no imaginoso afã de conciliar os dois textos, propõe, em parecer sobre o assunto, inaceitável distinção entre transação homologada em juízo contencioso e transação homologada, preventivamente, em processo voluntário ("Transação", em Rev. dos Tribs., $477 / 47)$.

A primeira estaria sujeita à ação rescisória do art. 485, VIII, ao passo que a segunda a ação de rescisão do art. 486 .

Como ROGERIO TUCCI considera uma das justificativas da pretensa ação rescisória o fato de o juiz, na transação, "averiguar o seu conteúdo, a par da consialação da observância dos preceitos legais que sobre o ato compositivo da lide incidem" (Parecer cit., R. T., $477 / 53)$, - segue-se que cai esse autor em contradição, pois tal verificação formal deve realizar-se, também, no tocante à transação preventiva no processo voluntário, por ele afastada da ação rescisória.

8. Depois do penoso esforço desses eminentes processualistas no tentar conciliar o inconciliável, a conclusão a que se chega é que o equívoco está na interpretação, visto como nenhuma lei do mundo pode distorcer a verdade objetiva das coisas, de modo a criar o absurdo, a transformar dois mais dois em cinco.

Com efeito, o grande mestre que é ALFREDO BUZAID não cometeria o erro palmar de impor ação rescisória para desconstituir simples homologação, sem nenhum conteúdo decisório da lide, em que pese a reconhecida falta de clareza do Código no trato do assunto.

No Anteprojeto, a redação por ele dada ao inciso VIII do atual art. 485 fora esta:

"Quando foi revogada, ou houve fundamento para revogar, confissão, desistência ou transação, em que se fundou a sentença".

Esse texto se inspirava na antiga redação do art. $771,4 .^{\circ}$, do Código de Processo Civil português:

"A decisão transitada em julgada só pode ser objeto de revisão nos esguintes casos: (...)

"4. ${ }^{\circ}$ Quando se tiver revogado, ou houver fundamento para revogar, a confissão, desistência ou transação, em que se fundou a sentença". 
Desde logo cumpre observar que no direito português não existe ação rescisória. A revisão, bem ou mal, é considerada recurso, integrando a Seção VI do Capítulo VI, "Dos Recursos", Título II do Livro III do Código. E é julgada pelo mesmo órgão que proferiu a sentença, (art. 772, n. ${ }^{\circ}$ 1).

Já se vê que, em tal sistema, não seria de repugnar a revisão de homologação formalmente transitada em julgado. Além do mais no Código português, a transação judicial se encerra, não por simples homologação, mas por autêntica sentença condenatória ou absolutória, de acordo com o que foi transigido (art. 300, ns. 3 e 4).

Ora, tal prática se afasta por completo da tradição e da letra de nosso direito. O art. 1028, I, do Código Civil, fala em termo "homologado pelo juiz", e o art. 584, III, do C.P.C. se refere a "sentença homologatória". Aliás, não teria sentido que a transação, destinada, como é, a prevenir ou eliminar litígio, fosse terminar em sentença condenatória, jurisdicional, litigiosa.

A interpretação do art. 485, VIII, do C.P.C., portanto, há de ser outra.

Quando o Código diz, no caput do artigo, que "a sentença de mérito, transitada em julgado, pode ser rescindida", refere-se apenas, de acordo com a boa doutrina sobre a ação rescisória, às sentenças que fazem coisa julgada material, que se tornam imutáveis porque julgam efətivamente a lide, como atos juridicionais, e não administrativos.

Exatamente por que o objeto da ação rescisória consiste na desconstituição do ato específico e fundamental do Poder Judiciário, que é a sentença jurisdicional, - exatamente por isto é que o Código the confere a dignidade e a situação singular de ser julgada em instância única, como causa da competência originária dos Tribunais.

Ora, isto não ocorre com a simples homologação, que, em regra, é ato administrativo praticado pelo juiz. Sua finalidade consiste, simplesmente, em formalizar o acordo para extinguir a relação processual, uma vez que a lide foi eliminada pela próprias partes, que dispensaram o juiz de julgá-la.

Como, entretanto, a ação pende em juízo, é natural que caiba ao juiz, como autoridade dirigente do processo, o dever administrativo de encerrá-lo com o ato homologatório, que tem a virtude, além do mais, de conferir eficácia executiva judicial ao pacto (art. 584, III), sem, contudo, em nada acrescê-lo quanto à substância. 
E a doutrina tradicional, assim exposta pelo insigne LAFAYETTE:

"A sentença de homologação não comunicaria ao contrato uma virtude que ele não tinha. E sabido que a homologação só tem por fim dar maior solenidade ao ało, mas não lhe dá, nem tira atributo algum. Nihil de novo dat - dizia o célebre DUMOULIN - nihil novi juris confert. É doutrina do Dirieto Romano, do Canônico, e a adołada no Direito dos povos culyos.

... ."Motivá 3 ou non, l'homologation est toujours un acte de jurisdiction volontaire et, à ce titre, elle ne peut produire l'autorité de chose jugée" (sentença). (LAURENT, Droit Civil, 20, n. 8)". ("Pareceres", 1. ${ }^{\circ}$ vol., p. 354).

Ou, como sustentou COSTA MANSO, consoante o étimo grego do vocábulo, "homologar não é decidir; homologar é confirmar" "Votos e Acórdãos", p. 238).

E PONTES DE MIRANDA, com absoluta precisão e clareza, em parecer anterior ao atual Código (que não soube intepretar neste ponto), coloca o assunto nos devidos termos:

"Houve, entre os juristas do século passado, quem levasse (em 1855) até à quase-assimilação, transação e sentença: C. RISCH ("Die Lehre vom Vergleiche", 'Erlangen, 1855, $26 \mathrm{~s}$. e 32); todavia, nem fora até às últimas consequências, nem o que ele escreveu resistiu às críticas que lhe foram feitas, especialmente à de OSKAR BULOW ("Absoiute Rechtskraft", "Archiv für die civilistische Praxis", 83, 85 s., nota 95) A própria sentença homologafória não resolve; o negócio jurídico da transação é que lhe faz o fundo; transita em julgado, formalmente; não produz força de coisa julgada material, a peito da proposição que se insere no art. 1030, 1. a parte.

"A sentença só decide integrar a forma do negócio jurídico. Ou pela juntada, ou por ter sido feita por termo nos aułos, a transação já está no processo, já é ato processualizado ou ato processual. A homologação integra-o, torna-o irradiador do efeito que mais se tinha em mira: o efeito extintivo da relação jurídica processual. Após a homoiogação, ela e o negócio júrídico da transação aparecem como um łodo, mas sem que se lhes apague a procedência: o negócio jurídico tem os efeitos que 
resultam do que foi acordado e tem a sorte dos outros negócios jurídicos da sua classe; a homologação não deixa de ser ato sentencial, que se há de tratar como sentença e exposto à sorte das sentenças da sua classe". ("Tratado de Direito Privado", tomo XXV, 170). (...)

"Uma vez que deixou de existir a relação jurídica processual, se um ou alguns dos figurantes se recusaram a cumprir o que consta do negócio jurídico transacional, - caminho único é o de se propor a ação adequada, pois, com a sentença homologativa, deixou de existir qualquer ato processual. (...)

"A decisão que homoioga a transação é decisão transparente e entra na claslse das decisões a que se refere 0 art. 800, parágrafo único, do $\mathrm{CPC}^{\prime \prime}$. (de 1939).

"A homologação dos negócios jurídicos é uma das espécies de atividades da jurisdição voluntária. Aí, há participação do Estado para integração dos negócios jurídicos, como existe nas funções registrárias e certificałtivas. A homologação de negócios jurídicos serve, quase sempre, à solução de contendas, porém aí não há sentença que decida a questão ou as questões". (Parecer, de $22 / 3 / 72$, em R.T., 441, ps. 39, 40 e 42).

As decisões homologatórias "se limitam a autenticar a vontade das partes", como afirmou o 3. " Grupo de Câmaras Civis do Tribunal de Justiça de São Paulo (R. T., 405/202).

Por isto, como acentua o Supremo Tribunal Federal, "não há confundir a ação rescisória com a de rescisão ou anulatória. Esła só diz respeito aos atos jurídicos passíveis de invaiidação, sem que haja coisa julgada, hipółese em que entra aquela, para tucio desfazer". R.E. n. 6.797, em Arq. Judiciário, 69/112).

No mesmo sentido, a 3. ${ }^{\text {a }}$ Câmara Civil do T. J. de São Paulo: "Se a sentença é simplesmente homologatória da vontade das partes, é ato de jurisdição graciosa", "'não faz coisa ulgada", "não sendo hipótese de rescisória". (R T , 353/214).

9. Assentadas estas premissas, ou seja, que o art. 485 do Có. digo se refere apenas, de acordo com a boa doutrina, à rescisão de sentenças de jurisdição contenciosa, que transitam materialmente em julgado, porque julgam a lide, eliminando o conflito com a declaração do direito em concreto, como norma de conduta às partes desavindas (coisa que não existe na homologação), - estamos em 
condições de interpretar, com acerto e correção, o inciso VIII do referido artigo, distinguindo-o da hipótese prevista no art. 486, destinado à ação anulatória.

A distinção é simples. Basta considerar-se que a transação pode ser objeto tanto de sentença homologatória sem lide (já terminada pelas partes), quanto de sentença jurisdicional litigiosa nela baseada.

Apenas a esta última hipótese é que se refere o inciso VIII do art. 485 .

Em dois casos poderá ocorrer sentença jurisdicional baseada em transação.

Em primeiro lugar, a transação, como é sabido, constitui fato extintivo do pedido, assim considerada pelo direito civil, que a equipara a outros atos extintivos de direitos e obrigações, como a novação, etc.

Como tal, pode a transação ser oposta em defesa pelo réu (art. 326 do C.P.C.), como ato anterior - judicial ou extrajudicial, pouco importa - à ação onde pretende o autor reiterar a lide sobre matéria já transigida. Neste caso, como acentua CLÓVIS BEVILAQUA, pode o réu opor a "exceptio litis per transacionem finitae". ("Cód. Civ. Com.", 5." ed., IV/190, coment. ao art. 1030).

Ora, se isto acontecer, e se a sentença acolher a exceção, estaremos em presença de um dos casos de decisão jurisdicional baseada em transação, rescindível pelo inciso VIII, se esta puder ser invalidada.

Como exemplos desta última espécie, podemos citar casos julgados pelo Supremo Tribunal Federal (A.I. 15.252, 22/1/52, Arq. Jud., 105/27), pela 4. ${ }^{a}$ Câmara Civil do T. J. de São Paulo (12/6/58, 277/267 e pela 5.a Câmara Civil do mesmo Tribunal, relatado este pelo hoje Ministro RODRIGUES ALCKMIN (5/12/69, R.T. 413/193).

Também aqui haverá sentença jurisdicional baseada em transação rescindível nos termos do referido inciso VIII.

Isto significa que, em matéria de transação, a ação rescisória só será empregada quando houver sentença jurisdicional que resolva lide reiterada, e o faça por acolher o fato extintivo da transação anterior, celebrada fora do processo (extrajudicial), em outro processo ou no mesmo processo, transação que possa ser invalidada na rescisória. 
Que esta é a interpretação exata, lógica, coerente e sistemática do Código, basta que se considere que a transação inválida é posta pelo inciso VIII, como causa de rescisão da sentença, no mesmo plano da confissão e da desistência inválidas.

Ora, se o Código cogitasse de submeter à rescisória meras sentenças homologatórias, o dispositivo não teria nenhum sentido quanto à confissão, pois é evidente que os processos em que esta ocorre não se enorram por "homologação" da confissão, e, sim, por sentença jurisdicional de mérito, desfavorável ao confitente.

O de que o Código cogita, pois, no inciso VIII do art. 485 é da rescisão dessa sentença jurisdicional, quando baseada em confissão inválida, idéia ,aliás, que se torna clara no art. 352, II do qual aquele inciso é mera repetição: "A confissão, quando emanar de erro, dolo ou doação, pode se revogada por ação rescisória, depois de transitada em julgado a sentença, da qual constituir o único fundamento".

O mesmo vale para a transação e a desistência: o que constitui objeto da rescisória é a sentença jurisdicional, proferida "'inter nolentes", com base em transação ou desistência inválidas, e não, a mera homologação "inter volentes", que não transita materialmente em julgado.

Quando, pois, não houver reiteração de lide já transigida, mas tão só homologação voluntária de acordo das partes, não tem sentido o emprego da rescisória para desconstituí-lo. A hipótese se enquadra de modo cabal e indiscutível no art. 486 do C.P.C., isto é, na ação de rescisão, ou anulatória, do ato homologado, a ser movida em primeira instância, pelas vias comuns, sem as galas da instância única da rescisória no Tribunal Superior, eis que inexiste, na espécie, a coisa julgada material, própria da verdadeira jurisdição.

10. Mas, dir-se-á, o Código, no art. 269, III, afirma que o processo se extingue com julgamento de mérito quando as partes transigirem. Então, haverá julgamento de mérito na transação?

Não, à toda evidência.

Trata-se de impropriedade do Código que deve ser interpretada com inteligência e bom senso. Se as partes transigem, a homologlação conseqüente, como se viu, não julga a lide, porque esta não mais existe, eliminada como foi pelo acordo dos litigantes.

Como interpertar, pois, o dispositivo citado, para evitar-se o absurdo de "criar-se" um julgamento de mérito onde ele não existe, nem pode mais existir? 
A solução é fácil, e se ajusta ao sistema legal. Note-se que o Código, no art. 584, III, considerou a sentença homologatória da transação título executivo judicial.

Equiparou-a, portanto, quanto aos efeitos, à sentença de mérito transitada em julgado. equiparação que já constava do Código Civil, art. 1030, quando atribuiu à transação efeito idêntico ao da coisa julgada.

Nesta mesma linha, pois, deve ser interpretado o art. 269; III, do C.P.C. Quando nele se afirma que na transação se extingue o processo "com julgamento de mérito", o que se visa na verdade significar é que na transação há uma equiparação de efeitos com a sentença de mérito; não, que haja identidade de substância com este ato jurisdicional.

EGAS MONIZ DE A.RAGÃO, ao comentar o referido art. 269, III, fê lo com acuidade, soube captar-lhe o sentido de mera equivalência, em perfeita síntonia com a interpretação que defendemos:

"Ş o processo já estiver em curso, a transação o extinguirá, sem que o juiz profira sentença, vale dizer, a composição da lide resulta do ato de vontade das partes, que excluem a solução jurisdicional. Por esse motivo, CARNELUTTI a considera um "equivalente jurisdicional" ("Insfituciones, ns. 58-59, ps. 77/78), pois a lide é composta sem intervenção do juiz, mas com resulłado igual ao que seria alcançado por seu intermédio". ("Comentários", II/461).

Já LAURENT afirmava, com razão, que as transações são convenções que se formam "par concours de consentement et non par la décision du juge". ("Principes", 28/365).

Essa equivalência de efeitos para atos substancionalmente diversos e distintos em nada aberra da doutrina e do bom senso.

O Código, por igual, atribui efeito executório a títulos extrajudiciais, e nem por isto chegar-se-á ao absurdo de identificar a promissória ou o cheque a uma sentença, de tal modo que se pense em desconstituí-los através de ação rescisória.

Aliás, PONTES DE MIRANDA jamais estabeleceu identidade entre transação e coisa julgada. Limitou-se apenas a afirmar que a homologação daquela "transita em julgado formalmente, não produz força de coisa julgada material". ("Tratado", 25/170). E CLOVIS já acentuava que o Código Civil "não diz que a transação tem autoridade de 
coisa julgada. Diz apenas que ela produz efieitos de coisa julgada". ("Cód. Civ. Com.", IV/189).

11. Restabelecida, assim, a verdadeira interpretação dos arts. 485, VIII ,486 e 269, III, do C.P.C., de um modo sistemático e coerente, sem brigas com a realidade e ofensas ao senso comum, resta examinar ainda um último argumento, lançado por ROGERIO TUCCl, como se viu acima: a sentença homologatoria de transação seria jurisdicional porque o juiz deve verificar se os pressupostos legais desse ato jurídico foram atendidos na espécie, antes de homologá-lo.

Ora, controle de legalidade não constitui atividade privativa do Poder Judiciário, e sim comum a todos os Poderes do Estado. Também a autoridade executiva, a todo momento, deve vigiar pela legalidade dos atos que the são submetidos, ou dos quais participa.

Não é esse traço que singulariza a jurisdição. $O$ juiz por igual exerce controle de legalidade na chamada "jurisdição" voluntária, como nos desquites por mútuo consentimento, atividade de natureza administrativa, como sói acontecer com todas aquelas que se enquadram na referida "jurisdição", como é notório.

Nada demais, pois, que ao homologar a transação verifique formalmente se os pressupostos legais do ato se cumpriram. Trata-se de exame externo, sem entrar no mérito da composição da lide, que pertenceu todo à autonomia da vontade das partes.

À toda evidência, essa verificação formal, de caráter meramente administrativo, não possui força suficiente para transformar a homologação em sentença jurisdicional de mérito, de modo a sujeitá-la à disciplina da ação rescisória.

12. Restaria, ainda, uma dificuldade aparente: E se a sentença homologatória for proferida por juiz incompetente?

Certa doutrina, mesmo na vigência do Código anterior, reclamava nesta hipótese o emprego da rescisória. Não compartilhamos, porém, dessa opinião.

Se relativa a incompetência, o contrato transacional ou a conciliação importam prorrogação de competência, ou porque a exceção não foi oposta, ou porque, se argüida, dela terá havido desistência, expressa ou tácita, pouco importa, fato que consolida a competência do juízo homologatório.

Se absoluta a incompetência ,haverá, tão só, nulidade dos atos decisórios, inclusive da homologação (art. 113, § 2. ${ }^{\circ}$ ), mas perduram a transação, o acordo ou a conciliação, como contratos entre as partes, 
os quais permanecem válidos, pelo princípio da conversão, como se se tratasse de transação extrajudicial, extintiva do litígio.

Aliás, é freqüente a opção das partes pela transação extrajudicial, na pendência da lide, com posterior desistência da ação.

A transação judicial, homologada por juiz absolutamente incompetente, possui a mesma eficácia da extrajudicial em tal hipótese, salvo se o respectivo ato jurídico se apresentar com algum elemento próprio e específico de ineficácia, como se lavrado por instrumento particular quando a lei o exigir público.

Mas, se inocorrer vício intrínseco ou extrínseco a ele pertinente, o contrato transacional permanece como ato extintivo da lide, eficaz entre as partes, no que concerne aos direitos e obrigações recíprocos neel estabelecidos.

Haverá, apenas, em virtude da nulidade da homologação perda da eficácia executiva judicial (art. 584, III) embora possa manter-se análoga eficácia, mas extrajudicial, se do acordo constar obrigação de pagar quantia determinada ou de enregar coisa fundível, e o documento se revestir das características prescritas no inciso II art. 585 .

Se tal não suceder, desprovida a transação em referência de eficácia executiva judicial ou extrajudicial, seu inadimplemento por qualquer das partes reclamará apenas, do lesado, propositura de ação de conhecimento nela fundada, em face da permanência do respectivo vínculo obrigacional.

Se, acaso, a transação homologada por juízo absolutamente incompetente contiver vício que a invalide, ainda assim desnecessária se faz a rescisória. Bastará, para desconstituí-la, o uso da arulatória pelo autor, ou da exceção correspondente, em resposta, pelo réu.

13. Do exposto resulta, em última análise, que, na verdade, - Código atual não modificou o anterior quanto ao remédio adequado para desconstituir transação, ou acordo, ou conciliação, homologados por sentença.

Como esta última não possui natureza jurisdicional, clecisória da lide, e como o ato material visado é, substancialmente, o acordo de vontades das partes, rescindível (ou, melhor, anulável) "como os atos jurídicos em geral, nos termos de lei civil", incide, à toda evidência, a norma do art. 486, idêntica à do parágrafo único do art. 800 do Código de 39, isto é, a ação desconstitutiva adequada é a comum, de nulidlade ou anulatória, aforável em primeiro grau, e 
não a ação rescisória, própria para atacar, tão só, as sentenças jurisdicionais que adquirem a imutabilidade da coisa julgada material.

Felizmente, jurisprudência plasmada já na vigência do novo Código se tem esquivado das perplexidades e laboriosas construções acima referidas, e vem mantendo o bom senso e o acerto da tradição de nosso direito a respeito do assunto.

O Primeiro Grupo de Câmaras Civis do Tribunal de Justiça de São Paulo, em acórdão de 7.12.76, decidiu que "a ação rescisória somente tem pertinência para rescindir sentença de mérito e não acordo celebrado pelas partes" (R.T., 502/103). No mesmo sentido, a Terceira Câmara Civil do mesmo Tribunal, quanto a acordo em ação de alimentos, em acórdão de 23.9.76 (R.T., 496/101).

Acolhendo ensinamento de ERNA.NE FIDELIS DOS SANTOS ("Estudos de Direito Processual Civil", Uberlândia, 1975, p. 116), no mesmo sentido da tese que ora sustentamos, as Câmaras Civis Reunidas do Tribunal de Justiça de Minas Gerais, em acórdão de 1.4.76, assentaram que "a decisão homologatória de transação judicial é rescindível pela mesma maneira como o são os atos jurídicos em geral, e não mediante ação rescisória". (EDSON PRATA, "Repertório de Jurisp. do C.P.C."”, 8/2589, n. 1999).

Lamentável é que, na Justiça do Trabalho, se tenha generalizado o erro de impor-se ação rescisória contra simples homologações de conciliação ou acordo, sobrecarregando-se, assim, desnecessariamente, com prejuízo para a prova e ofensa ao princípio da dualidade de instâncias, a pauta dos Tribunais de segundo grau com feitos que, na verdade, pertencem, como simples demandas anulatórias, à competência dos Juízos inferiores, quando deles emanarem as respectivas homologações.

Ao assumirmos a defesa dos princípios, em exegese sistemática no novo Código, esclarecedora dos equívocos que têm perturbado a doutrina, fazemo-lo com o intuito de contribuir para que se afirme e mantenha, em todo o País, a jurisprudência tradicional sobre a ação rescisória, remédio que deve ser preservado, em sua alta dignidade de feito da competência originária dos Tribunais, para a desconstituição da coisa julgada material imutável, efeito mais importante das sentenças jurisdicionais no processo civil, e não para simplesmente anular transações, atos de parte meramente homologáveis, suscetíveis dos vícios do ato jurídico em geral. 